\title{
The Prevalence and Pattern of Superficial Fungal Infections among Patients Visiting Dermatology OPD of a Tertiary Care Hospital in Warangal
}

\author{
G. V. Padmaja, Efshana Jabeen* and Anushya \\ Department of Dermatology, Kakatiya Medical College, Warangal, India \\ *Corresponding author
}

\section{Keywords}

Superficial,

Subcutaneous, and Systemic depending on the degree of invasion of the host

Article Info

\section{Accepted:}

20 February 2020

Available Online:

10 March 2020

\section{A B S T R A C T}

Fungal infections or mycoses are classified as Superficial, Subcutaneous, and Systemic depending on the degree of invasion of the host. Superficial fungal infections are most common in tropical and subtropical countries. Superficial fungal infections of the skin are one of the most common dermatological conditions seen in clinical practice. It affects 20$25 \%$ of the population. In this study, 1473 Suspected superficial fungal infection cases were identified among approximately 3500 patients screened during August 2017 to August 2019. The collected samples (skin, nail, and hair) were subjected to direct microscopy with $10 \%$ potassium hydroxide and cultured on plain Sabourauds dextrose agar, Sabourauds dextrose agar with actidione and Sabourauds dextrose agar with chloramphenicol. After the fungal culture growth Lacto Phenol Cotton Blue mount was done to identify the fungal species. The prevalence of superficial fungal infection was $26.2 \%$ (386/1473), dermatophytosis was $63.7 \%$ (246/386), and non-dermatophytosis was $36.3 \%$ (140/386). Among the isolated dermatophytes, Trichophyton rubrum was the commonest species $(68 \%)$. and Candida $(70 \%)$ the commonest non-dermatophytes species. Tinea corporis wasthe commonest (58\%) clinical presentation. Culture examination highlighted dermatophytes 68\%Trichophyton rubrum, $19 \%$ Trichophytonmentagrophyte, 6\% Trichophyton tonsurans, $2 \%$ Trichophyton violaceum, $2 \%$ Microsporum gypseum, $1.5 \%$ Microsporum canis, $0.9 \%$ Trichophyton verrucosum 0.5\% Epidermophyton floccosumand non-dermatophytes 38\% Candida albicans, 32\% Candida non albicans 10\% Aspergillus niger, 7\% Aspergillus flavus, 4\% Aspergillus fumigatus, $1 \%$ Aspergillus ptereus, 3.5\% Malassezia furfur, 2\% Alternaria, 2\% Curvularia and $0.5 \%$ Cladosporium werneckii. The current study illustrates that a notable number of patients had prevalence of superficial fungal infections, hence a prompt recognition of skin lesion and identification of these superficial fungal infections alarms us to undertake early diagnosis and treatment to improve the quality of life.

\section{Introduction}

Fungal infections affect majority of mankind and of them superficial fungal infections are most common.it is prevalent in many countries but in countries with high humidity like in India its prevalence is more common. Superficial fungal infections can be dermatophytic and non dermatophytic in origin. In the recent past there has been 
increase in rates of non dermatophytic skin infections due to increase in steroid abuse, irrational use of over the counter ointments, increase in immunocompromised conditions, diabetes etc. The present study was done to find out the clinical pattern of dermatophytes and non-dermatophytes and to identify the commonest pathogen.

\section{Materials and Methods}

It was a hospital-based cross-sectional study conducted in a tertiary care hospital in Warangal, Telangana India between August 2017 to August 2019.A total of 1473 Suspected superficial fungal infection cases were identified among approximately 3500 patients screened in department of dermatology of our tertiary care hospital.

Patients with suspicious skin lesions having central clearing or symptoms like redness (erythema), scaly nature of skin (hyperkeratosis), dryness, itching (pruritus), plaques with uneven borders, discoloration, vesicles etc were examined and samples were collected from them. Based on the affected skin area it was diagnosed provisionally as Tinea cruris, tineac apitis, Tinea corporis, Tinea mannuum, Tinea pedis etc. A nail infection is suspected when there is distal hyperkeratosis, when chalky and dull yellow debris is found under the nail if it is separated from its bed, and the nail plate is brittle. Hair infection when scalp skin has red to purple rash, scaling, dandruff, patches, white, flaky, moist may or may not be accompanied by hair fall.

With above said features patient's samples were collected. Patients who had not been on prior anti-fungal were taken up in this study. Under thorough aseptic precautions with use of scalpel, skin scrapings were taken from lesions, similarly nail clippings and hair plucking were taken from suspected cases as per standard procedure and were subjected to direct microscopy with $10 \%$ potassium hydroxide (skin) and $40 \%$ potassium hydroxide(nail). Samples which were positive for fungal elements like spores and hyphae were noted. These were then cultured on plain Sabourauds dextrose agar, Sabourauds dextrose agar with actidione and Sabourauds dextrose agar with chloramphenicol. Incubated at 25 degrees centigrade. Cultures were examined weekly to detect any fungal colony growth and its obverse reverse morphological characters were noted.

After the fungal culture growth Lacto Phenol Cotton Blue mount was done to identify the fungal species. Care was taken to avoid and rule out any kind of contamination.

\section{Results and Discussion}

Around 3500 cases were screened during 2 years study period from August 2017 to August 2019 and among them 1473 were suspected to have superficial fungal infection. The prevalence of superficial fungal infection was $26.2 \%$ (386/1473). Tinea corporis was the commonest $(58 \%)$ clinical presentation. Dermatophytes were $246 / 386$ more common. Non dermatophytes comprised of $36.3 \%$ of the total superficial fungal infections (140/386) and they affected more than one site of the body, but nails and feet were more commonly affected.

\section{Discussion}

In this study 386 cases were confirmed by clinical diagnosis to have superficial fungal infection. based on the region many had occupational background in farming, agriculture, animal husbandry, poultry, meat shop and veterinary personnel. History of immunocompromised status and old age was also common. Workplace exposure and social status seemed to be causative factors. 
Table.1

\begin{tabular}{|c|c|c|c|c|c|c|}
\hline Dermatophyte & Corporis & Cruris & Mannuum & Faceii & Pedis & Capitis \\
\hline $\begin{array}{l}\text { Total no. } \\
\{\%\}\end{array}$ & $\begin{array}{l}143 \\
(58 \%)\end{array}$ & $\begin{array}{l}29 \\
(12 \%)\end{array}$ & $\begin{array}{l}17 \\
(7 \%)\end{array}$ & $\begin{array}{l}12 \\
(5 \%)\end{array}$ & $\begin{array}{l}20 \\
(8 \%)\end{array}$ & $\begin{array}{l}25 \\
(10 \%)\end{array}$ \\
\hline $\begin{array}{l}\text { T. rubrum } \\
167\{68 \%\}\end{array}$ & $\begin{array}{l}95 \\
(56.8 \%)\end{array}$ & $\begin{array}{l}21 \\
(12.5 \%)\end{array}$ & $\begin{array}{l}12 \\
(7.1 \%)\end{array}$ & $\begin{array}{l}11 \\
(6.5 \%)\end{array}$ & $\begin{array}{l}7 \\
(4.1 \%)\end{array}$ & $\begin{array}{l}21 \\
(12.5 \%)\end{array}$ \\
\hline $\begin{array}{l}\text { T. mentagro-phytes } \\
47\{19 \%\}\end{array}$ & $\begin{array}{l}28 \\
(59.5 \%)\end{array}$ & $\begin{array}{l}6 \\
(12.7 \%)\end{array}$ & $\begin{array}{l}2 \\
(4.2 \%)\end{array}$ & $\begin{array}{l}1 \\
(2.1 \%)\end{array}$ & $\begin{array}{l}6 \\
(12.7 \%)\end{array}$ & $\begin{array}{l}4 \\
(8.5 \%)\end{array}$ \\
\hline $\begin{array}{l}\text { T. tonsurans } \\
15\{6 \%\}\end{array}$ & $\begin{array}{l}11 \\
(73.3 \%)\end{array}$ & $\begin{array}{l}2 \\
(13.3 \%)\end{array}$ & - & - & $\begin{array}{l}2 \\
(13.3 \%)\end{array}$ & \\
\hline $\begin{array}{l}\text { T. violaceum } \\
5\{2 \%\}\end{array}$ & $\begin{array}{l}3 \\
(60 \%)\end{array}$ & - & - & - & $\begin{array}{l}2 \\
(40 \%)\end{array}$ & \\
\hline $\begin{array}{l}\text { M.gypseum } \\
5\{2 \%\}\end{array}$ & $\begin{array}{l}2 \\
(40 \%)\end{array}$ & - & - & - & $\begin{array}{l}3 \\
(60 \%)\end{array}$ & \\
\hline $\begin{array}{l}\text { M.canis } \\
4\{1.5 \%\}\end{array}$ & $\begin{array}{l}2 \\
(50 \%)\end{array}$ & - & $\begin{array}{l}2 \\
(50 \%)\end{array}$ & - & - & \\
\hline $\begin{array}{l}\text { T. verruco-sum } \\
2\{0.9 \%\}\end{array}$ & $\begin{array}{l}2 \\
(100 \%)\end{array}$ & - & - & - & - & \\
\hline $\begin{array}{l}\text { T. floccosum } \\
1\{0.5 \%\}\end{array}$ & - & - & $\begin{array}{l}1 \\
(100 \%)\end{array}$ & - & - & \\
\hline
\end{tabular}
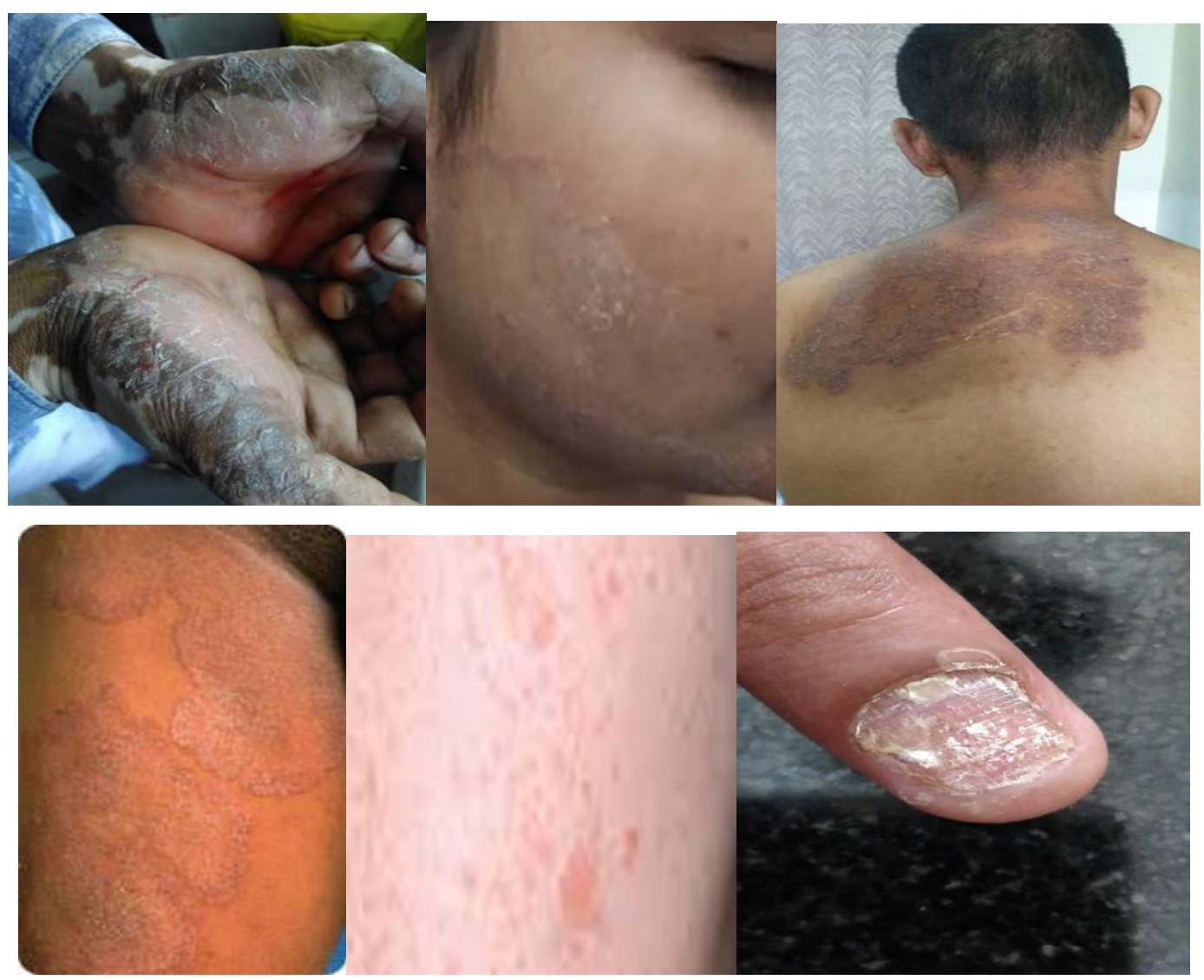

Fig.1 Fungal Infections Clinical Picture 

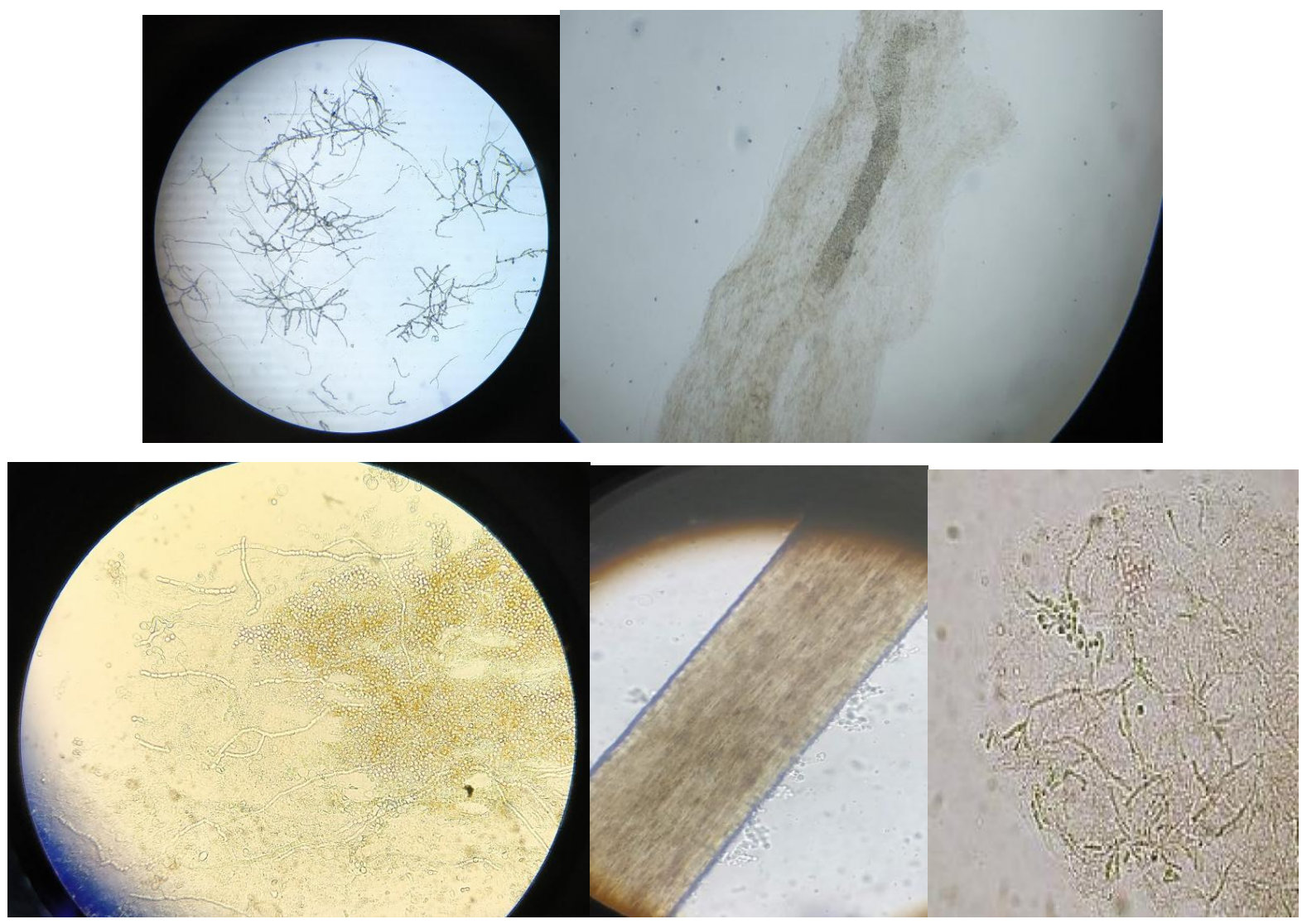

Fig.2 Images Of Koh Mount

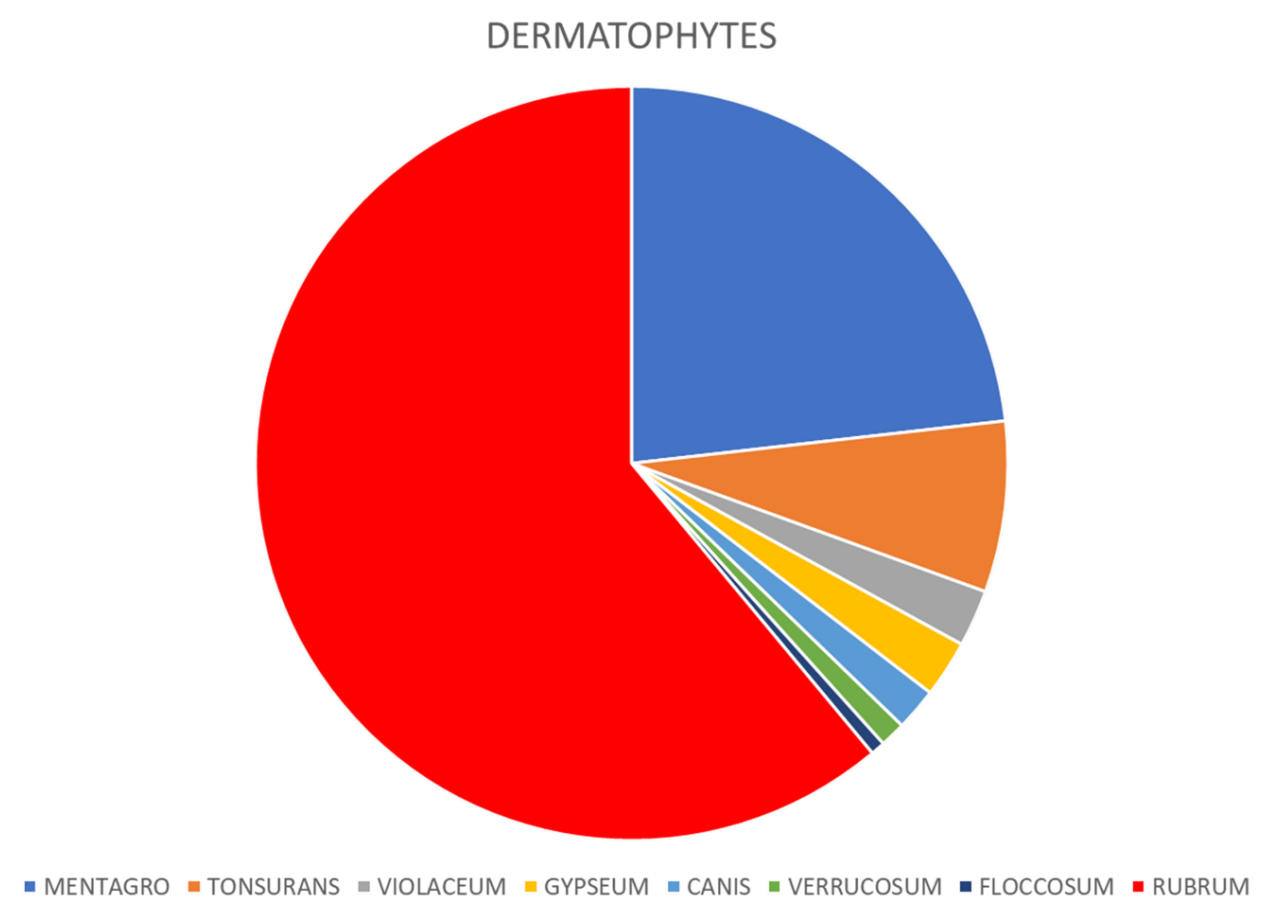

Fig.3 Dermatophytes 

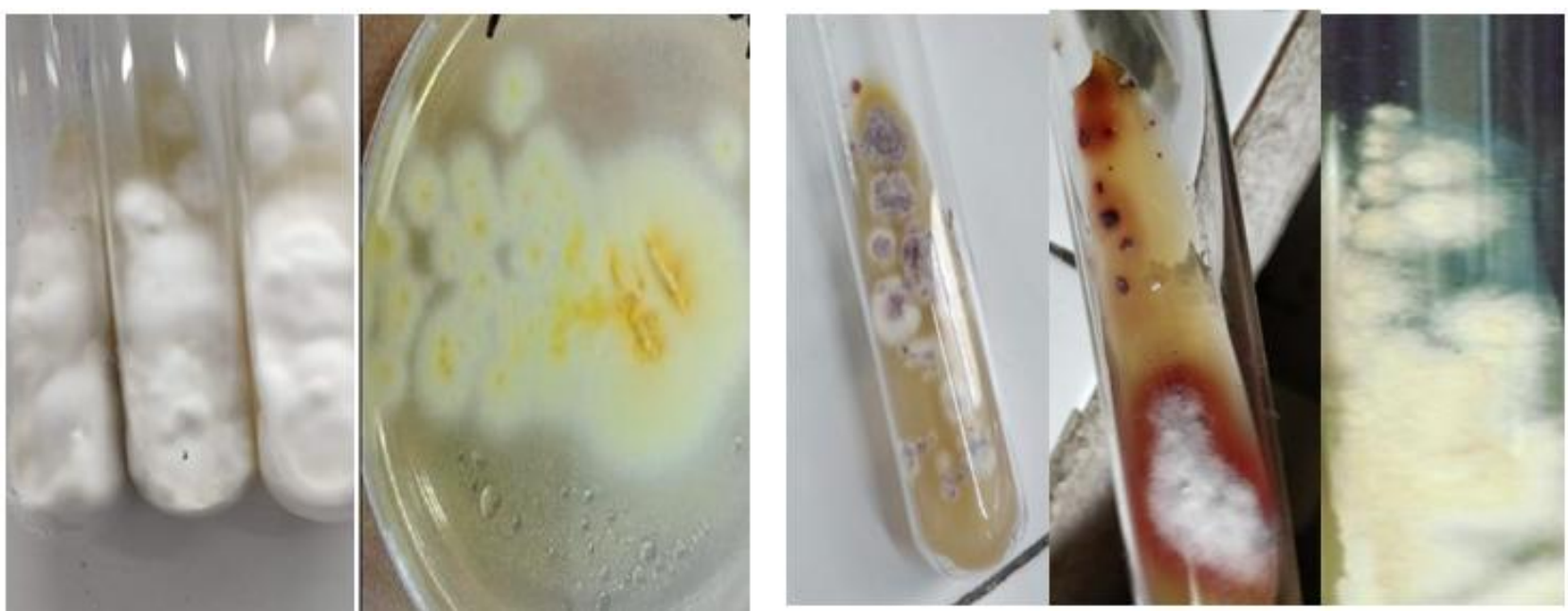

Fig.4 Dermatophyte Growth On Sda With Actidione

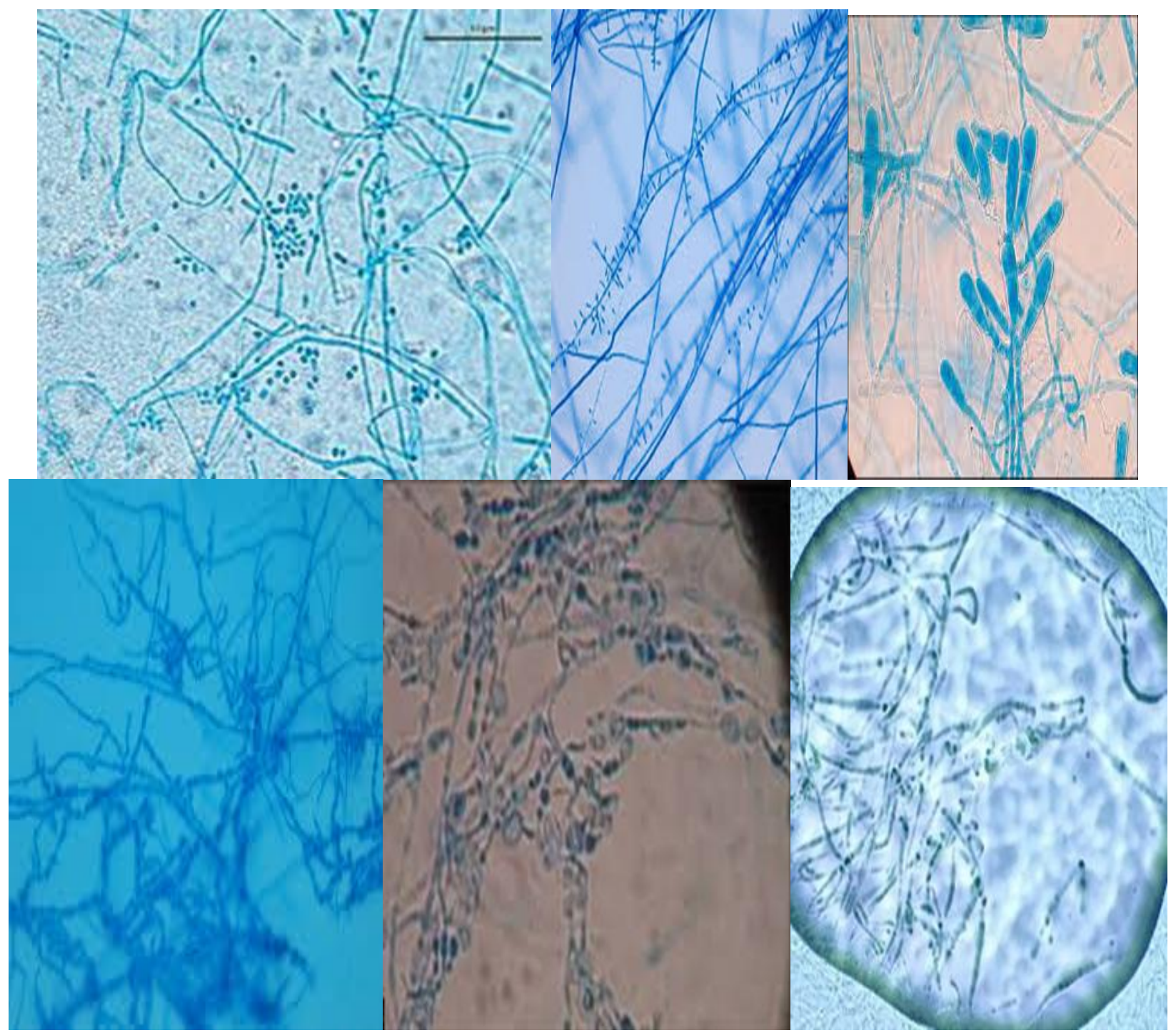

Fig.5 Dermatophytes Under Microscope After Lpcb Mount 


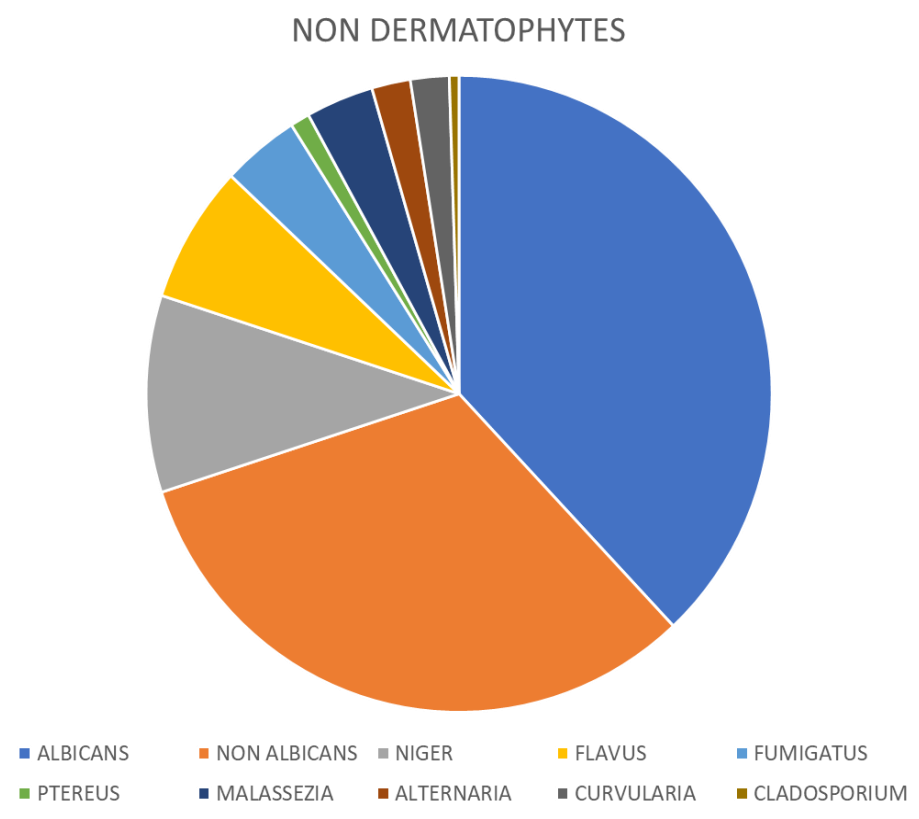

Fig.6 Non Dermatophytes

\begin{tabular}{|l|l|}
\hline Non-dermatophytes & Percentage \\
\hline Candida albicans & $38 \%$ \\
\hline Candida non-albicans & $32 \%$ \\
\hline Aspergillus niger & $10 \%$ \\
\hline Aspergillus flavus & $7 \%$ \\
\hline Aspergillus fumigatus & $4 \%$ \\
\hline Aspergillus ptereus & $1 \%$ \\
\hline Malassezia furfur & $3.5 \%$ \\
\hline Alternaria & $2 \%$ \\
\hline Curvularia & $2 \%$ \\
\hline Cladosporium werneckii & $0.5 \%$ \\
\hline
\end{tabular}

Public health awareness in such fields is hence very important and protocols should be made to follow hygiene at all places. Inappropriate use of steroids should be avoided. Tinea corporis was commonest [58\%] followed by Tinea cruris [12\%], capitis [10\%] and Tinea pedis [8\%].in our tertiary care setup Tinea faceii [5\%] was not a common presentation. These findings are similar to studies by Lakshmana et al., ${ }^{1}$ and Mishra et al., ${ }^{2}$ Amongst dermatophytes $T$. rubrum was most common, but important to be noted is high prevalence of urease positive dermatophyte $T$. mentagrophytes seen in our study. This shows increased emergence of dermatophytes. Non dermatophytes have also been emerging as causative agents of onychomycosis and superficial mycosis. All this lead to show increase in fungal infections and total increase in superficial fungal infections in particular. Hence public should be made aware and advised to visit dermatologist in the initial stage of infections, over the counter steroid use and antifungal cream use should be monitored, fungal examination should become necessary routine 
in all microbiological labs for aiding in patient's diagnosis and correct treatment as therapy varies from fungi to fungi.

\section{References}

1.Lakshmanan A, Ganesh Kumar P, Mohan SR, Hema Malini M, Madhavan R.
Epidemiological and clinical pattern of dermatomycoses in rural India. Indian J Med Microbiol 2015;33: S134-6.

2. Mishra M, Mishra S, Singh PC, Mishra BC. Clinicomycological profile of superficial mycoses. Indian J Dermatol Venereol Leprol 1998; 64:283-5.

\section{How to cite this article:}

Padmaja, G.V., Efshana Jabeen and Anushya. 2020. The Prevalence and Pattern of Superficial Fungal Infections among Patients Visiting Dermatology OPD of a Tertiary Care Hospital in Warangal. Int.J.Curr.Microbiol.App.Sci. 9(03): 2514-2520. doi: https://doi.org/10.20546/ijcmas.2020.903.288 